\title{
LA LIBERTAD EN EL FUNDAMENTO DE LA ÉTICA
}

\author{
Juan de Dios Vial Larraín \\ Facultad de Filosofía \\ Pontificia Universidad Católica de Chile
}

\section{Vivencia de la libertad}

Seguramente todos sabemos, de alguna manera, qué es la libertad y lo sabemos - o más bien lo presentimos- muy tempranamente; ya cuando ejercemos preferencias y creemos buscar nuestros propios caminos. Con temor, y aún angustia, vamos a la conquista de ese pedazo de mundo que queremos hacer propio y que miramos como nuestra personal tierra prometida. Sentimos la libertad como el sujeto de esta promesa.

Esta vaga intuición de nosotros mismos que desde muy temprano nos convoca, que interpela nuestro ser más íntimo, en la que oscuramente nos reconocemos, contiene ya la figura de la libertad.

En esa experiencia hay, a los menos, dos dimensiones: una noticia acerca de sí mismo, un saber en el que nos divisamos e identificamos como muy próximos y, a la vez, nos divisamos como distantes. En el que nos sentimos vivir, pero ante un gran horizonte incógnito; con personalidad entregada a nuestras propias manos, pero en una extensión indefinida.

La inteligencia y la voluntad dibujan su rostro en las aguas movedizas de esa experiencia primaria. La inteligencia, fundamentalmente como un saber de sí, conjugada con esa fuerza íntima, a la que se denomina voluntad. Percibimos desde el principio que somos libres porque nuestra voluntad es inteligente.

Pero, a la hora de aclarar en qué consiste esa identidad y poderío nuestro, su figura parece evadírsenos, dejándonos sólo su sombra. La libertad, pareciera reducirse nada más que a un juego de alternativas encaradas desde un lugar neutral con el que constantemente estamos encontrándonos y en virtud del cual cada vez debemos tomar una cosa pero dejar otra, siempre apremiados por el tiempo.

Y empezamos, inclusive, a sospechar cuánto de nosotros mismos hay en ese juego y cuánto de otras fuentes, en las cuales el mismo azar pareciera tener un papel descollante. Y se empieza a olvidar que, a través de la elección de alternativas, alguien, presente antes de ellas se constituye a sí mismo.

No necesitamos ser demasiado suspicaces para comprender que en el juego de alternativas los dados están marcados. Nuestra libertad parece una señal frágil, una efímera flor en el torbellino de circunstancias que condicionan todos los pasos de nuestra vida. Venimos así a preguntarnos ¿Es la libertad una apariencia, una ilusión, una mera aspiración; o es un ejercicio real de nuestra vida? ¿Estamos comprometidos en 
ella, somos en ella o es sólo un accidente pasajero, un índice algo borroso de las cosas que pasan por otras razones?

¿Hasta qué punto se es realmente libre? ¿En qué medida debe creerse, más bien, que todo está escrito y determinado? El cosmólogo francés Laplace aseguraba que si se le indicaba cuál era la posición de todas las partículas del Universo en un momento dado del tiempo, él -en virtud de las leyes de la física- estaba en condiciones de predecir todo lo que ocurriría después y de conocer todo lo ocurrido antes. Y cuando Napoleón le preguntó acerca de Dios, Laplace le habría respondido que esa era una hipótesis que no necesitaba. Freud, a su vez, habría mostrado que las motivaciones de nuestra conducta en definitiva se pierden en los profundos laberintos de la conciencia. Idea que ya podía leerse en alguna de las brillantes sentencias de Heráclito, aunque ese fondo inconsciente no necesariamente haya de reducirse a un nido de impulsos polimorfos y perversos como Freud parecía creer.

En fin ¿Será la libertad, más bien, una ficción, un engaño consolador para aligerarnos el yugo de esas necesidades ocultas? O algo quizá peor que han sugerido algunos biólogos contemporáneos: ¿Será la libertad otra cosa que una apariencia del mero azar?

\section{Se es libre para algo}

¿Qué puede ser la libertad que sentimos, en la que creemos, que defendemos, que quisiéramos dar a todos los hombres?. Permítanme insistir todavía. Si nos detenemos a reflexionar en lo que acerca de la libertad creemos saber por nuestra íntima experiencia, reconocemos que nos aventuramos hacia la profundidad más íntima de nuestro propio ser donde la sentimos latir. Esta es la experiencia fundamental. La libertad arranca del ser más propio, más íntimo, más personal del hombre. Pero tenemos que reconocer, a la par, que ese ser libre que somos y queremos ser, por su propia naturaleza no está terminado, no es una realidad hecha y acabada, sino justamente lo contrario, algo por hacer una tarea, una misión. Yo me siento libre. Pero fundamentalmente libre para algo. Y sé, a la vez, que esa libertad mia es frágil, que está condicionada y amenazada. Y que, quizá su mayor amenaza está en ella misma: precisamente por las decisiones que ha de tomar en su propio ejercicio. Tanto por las que toma como por las que deja de tomar. La libertad no es un episodio suelto: madura en el contexto personal de una vida.

Cuando usé la palabra "circunstancia" resonó en mi memoria aquella conocida fórmula de Ortega y Gasset: yo soy yo y mi circunstancia. Ortega no hablaba de una suma: yo + circunstancias. Hablaba de un yo circunstancial o circunstanciado, de una vida humana históricamente amasada. En este sentido la libertad es la clave de la ética. La libertad prefigura, posibilita y funda la ética, cualquiera sea su contenido.

Como estudiante de un colegio de jesuitas incomodé al profesor de filosofía que nos había explicado el libre albedrío, observándole que no veía manera de compatibilizarlo con la infinita sabiduría y omnipotencia de Dios que le permiten saber y decidir lo que ocurrirá y, además, tener poder para alterar su curso. Ya mayor he llegado a com- 
prender que en la sabiduría de Dios está justamente inscrita la libertad del hombre, quizá como la misma gloria del plan divino. De manera que la relación del hombre con Dios es bastante más íntima que la del amo y el esclavo, del escultor y la estatua o el ingeniero y la máquina. Que la propia acción de Dios pasa y se cumple en la misma libertad del hombre.

La falacia implícita en mi pregunta estaba en pensar desde el principio en términos de una mecánica determinista, en un antes y un después temporal como el que marcan los relojes y en una relación de causa y efecto como la del choque entre bolas de billar; modo de pensar que, desde luego, ni es el modo de hablar de Dios ni de llegar a comprender la libertad del hombre.

\section{Derecho y Filosofía}

Estoy bien consciente de que hablo en una Facultad de Derecho y no sólo me siento honrado por hacerlo sino que, además, me siento un poco en casa propia pues estudié derecho y soy Licenciado en estas disciplinas. Pero tampoco me considero un intruso por venir del campo de la filosofía a esta Facultad de Derecho.

Sé que cuando uno habla de libertad en el campo del derecho y de la sociedad, habla más bien de libertades y derechos, en plural. En tanto que en la filosofía se habla, más bien, de la libertad en singular. La Constitución dice, como Rousseau, que el hombre nace libre y da por entendido lo que esto significa, es decir, da la libertad por supuesta, y la explicita, luego, en la forma de derechos que la Constitución consagra y que fundamentalmente vienen a ser los que llamamos derechos humanos. Nótese todo lo que ahí va implicado: la libertad, el ser libre del hombre, como radicado en su propia naturaleza, en su misma humanidad, en aquello con lo que nace y que políticamente se expresa en un repertorio de derechos fundamentales, bien llamados, pues, derechos humanos.

Otro tanto ocurre en el campo del derecho privado, en donde damos por entendido que la libertad se manifiesta como autonomía de la voluntad, condición para la validez de un contrato, inclusive el de matrimonio. $Y$ sabemos que el contrato es nulo si no se lo celebra libremente, es decir, si se lo ha celebrado bajo el imperio de la ignorancia o de la fuerza y que, asimismo, en el orden penal no hay delito sino en esa forma de libertad que da a la acción un carácter doloso.

Hoy dia leemos esas cosas en el Código Civil o en el Código Penal. Pero así como la Constitución Política remite al pensamiento de Rousseau, en el Contrato Social, para establecer que el hombre nace libre, la idea de voluntad libre en tanto no constreñida por la ignorancia o la fuerza, de los Códigos modernos, es cosa que pudo leerse antes en la Ética Nicomaquea, el hermoso texto ético escrito por Aristóteles. Ética Nicomaquea y Contrato Social, son también fuentes del derecho.

Quiero decir así que la libertad toma en el campo del derecho formas bien definidas en las cuales la libertad misma se da por supuesta y se la entiende a la luz de determinadas concepciones filosóficas de las cuales no necesariamente se tiene con- 
ciencia, sino más bien, como he dicho, se las tiene por sabidas. Reflexionar acerca de la libertad, por consiguiente, no puede ser para el hombre de derecho una especulación gratuita, como pudiera serlo, quizá, la astronomía, sino que es una dimensión propia de los fundamentos de su mismo saber.

\section{Un saber que ignora}

Cuenta San Agustín en las Confesiones que cuando hablaba acerca del tiempo creía entender de qué estaba hablando, pero que cuando se detenía a preguntarse qué es el tiempo, reconocía que lo ignoraba. Este texto siempre me ha parecido admirable porque ese doble saber -el que cree conocer algo y el que advierte lo que ignora en su propio conocimiento- a mi entender desvela en su condición esencial el saber propio de la filosofía, hecho de experiencia real y de un género de ignorancia que quizá no sea sino una alta forma de saber; de un saber velado pero denso, rico de contenido latente y siempre abierto. Un saber que conoce su límite pero cuyo límite es esclarecedor, pues aclara lo ya sabido y abre un horizonte más allá de lo sabido. Creo que esta es la índole propia del pensar filosófico tal como se inicia en aquella sorprendente tesis de Sócrates: sé que nada sé; y que, a mi entender, viene a parar en otra tesis cargada de resonancias que Heidegger formulara: la pregunta es la piedad del pensamiento.

Quisiera, pues, preguntar por la libertad y reflexionar sobre la forma cómo la libertad ha sido pensada en la filosofía señalando los hitos que me parecen esenciales de la figura de la libertad en el pensamiento filosófico. El primero lo voy a sacar de la ética aristotélica; el segundo de la metafísica cartesiana y el tercero de la teoría kantiana del conocimiento en su proyección moral. Porque cuando se habla de libertad pareciera que todos hablan de lo mismo. Pero este os un gran equívoco. Lo que me propongo, entonces, nos es más que mostrar las difer icias esenciales que se descubren en el fondo filosófico de lo que se piensa cuando se habla de libertad.

Kant, en la modernidad, optó por una decisión muy radical que se convirtió en la clave de las más importantes respuestas éticas y políticas modernas. Kant admitió que el determinismo físico era cosa ineludible. Los movimientos del cielo estrellado, tal como podían ser explicados por la ciencia de Newton, le sumían en el más profundo respeto, le parecían el modelo del saber verdadero. Sobre el supuesto determinista, abonado por la ciencia moderna, la libertad no tendría sentido, sería una hipótesis innecesaria. Pero Kant admitió que hay un orden suprasensible regido de hecho por la propia libertad. Es decir, que habría un orden en el cual la libertad misma es un hecho-un factum- de pura índole racional. Esa razón práctica libre, de hecho y por principio, es para Kant la base del orden moral. El cual, por consiguiente, se edifica en un plano distinto al de la naturaleza física. Las leyes de la naturaleza, entonces, son deterministas y lo que hacen las ciencias es establecerlas; pero las leyes morales están imperadas por una autonomía absoluta de la libertad que se constituiría a espaldas a la naturaleza. Estas ideas fundamentales de la filosofía kantiana subyacen a las más diversas actitudes y posiciones propias de la conducta del hombre moderno. 
La visión de Aristóteles es bien distinta y sobre ella se edificó lo que cabe llamar moral natural en el pensamiento cristiano, es decir, aquella moral que no necesariamente haya de encontrarse en la revelación y en la fe, pero sí en la simple reflexión sobre la naturaleza de las cosas.

Descartes fue un heredero del pensamiento clásico y supo actualizarlo. Descartes no situó la libertad en un contexto moral, como Aristóteles, sino en el nudo de la metafísica. Kant rompió esta idea e hizo de la pura moral un absoluto metafísico.

\section{La virtud elige}

Comencemos por Aristóteles. La ética aristotélica es fundamentalmente una doctrina de la virtud. En el pensamiento moderno, y principalmente por obra de Nietzsche, se le ha quitado a la noción de virtud toda su antigua riqueza semántica. La virtud es una capacidad, una fuerza arraigada, constante, eficaz; la excelencia conquistada en algún campo de acciones y que llega a constituirse como una segunda naturaleza. Cicerón recordaba en Tusculanas (II, 8) que "virtud" proviene de vir, varón, que es sujeto de fuerza y fortaleza.

¿Cómo llega Aristóteles a la noción de virtud en la Ética Nicomaquea? Llega a partir de su descripción esencial de la naturaleza del hombre en el orden práctico. Dos rasgos enmarcan la antropología moral de Aristóteles. El primero es aquel que descubre la naturaleza del hombre en el gran escenario de la vida, y el segundo es el que la ve constituida por ese carácter tan esencial que los griegos llamaron logos y que ha venido a ser traducido como "inteligencia", "razón" y aun, sencillamente, "verbo". El hombre posee razón, es el animal dotado de logos, es el animal racional. La vida y la inteligencia, las pasiones y el logos, forjan la virtud en el pensamiento de Aristóteles.

Ahora bien el logos humano, en el orden práctico, es, para Aristóteles, un proyecto, es decir, la estructura de un fin. El hombre aspira a ser, quiere ser, está animado por tendencias que conspiran hacia algo todavía innominado pero que llama y convoca. Este campo de las tendencias del hombre está poblado de energías contrapuestas que Aristóteles llamó "pasiones", en el sentido de fuerzas que se padecen, que arrastran y que amenazan con sacar del camino; aunque también sean poderosas impulsoras del caminar humano. Entre pasiones y fines se va haciendo camino.

La razón del hombre tiene, así, una vertiente práctica. Esta es una distinción que llega hasta nosotros, que todos reconocemos aparentemente sin dificultad y que proviene de una antropología griega en la que el saber de las cosas no es lo mismo que lo que hacemos con ellas. Para Aristóteles, en la huella de Sócrates, la vertiente práctica de la vida tiene en la inteligencia su timón. El timón aprovecha la fuerza de las aguas y conduce la barca. Este timón es la misma razón constitutiva de la naturaleza del hombre ahora volcada a las circunstancias concretas de la vida, sus pasiones y sus fines.

El timón moral de la inteligencia práctica lo ejerce una virtud fundamental que Aristóteles denominó "prudencia" - phronesis en el griego- noción que a partir de la Ilustración se aburguesa pero que en el pensamiento aristotélico representa sencilla- 
mente la inteligencia de la acción. Esta virtud capital gobierna el puñado de virtudes con las que el hombre enfrenta las circunstancias en las que le toca vivir. Tales circunstancias son apetitos que parecen provenir del cuerpo, como el hambre o el deseo sexual, frente a los cuales hay una virtud que es el dominio de sí que se llamará templanza; o hay amenazas externas que nos llenan de temor y angustia, por ejemplo, el dolor y la muerte; frente a ellas la fuerza interior de una virtud que toma el nombre de valentía o fortaleza; o nos encontramos, en fin, en sociedad con otros hombres sujetos, por ende, a todas las vicisitudes que ello implica en el plano personal, político, económico. La acción humana gesta, entonces, una variada gama de virtudes: la justicia, la amistad, la fortaleza, el dominio de sí, la generosidad, la magnanimidad, la magnificencia, la gracia y otras descritas con finura en la Ética Nicomaquea.

Pues bien, a la hora de definir en qué consiste propiamente la virtud, Aristóteles dice, justamente que consiste en la capacidad de elegir que forja una educación, una cultura, una práctica. Capacidad de elegir el medio apropiado a la perfección personal. Por consiguiente, la libertad, para Aristóteles, es eminentemente fruto de la acción virtuosa. Y en ella la inteligencia, la razón práctica, y los deseos e impulsos que configuran la voluntad, se conjugan y unifican en la estructura de la vida humana. Aristóteles dice que hay una "inteligencia deseosa" que es, a la vez, "deseo inteligente" y luego de decirlo, dentro de un estilo muy peculiar de sus escritos, afirma con rotundidad: "Esto es el hombre". La libertad está implantada en la realidad misma del hombre y se ordena, dentro de un mundo real e histórico, a su perfección personal.

\section{Libertad de la inteligencia}

La filosofía de Descartes conduce por otra vía a ese mismo punto. Ustedes saben que la filosofía de Descartes arranca de la duda, precisamente como deseo de saber. En el siglo XVI, en cuyos últimos años nació Descartes, prevalecía el escepticismo. Un filósofo español tituló su libro Que Nada se Sabe. Pues bien, Descartes le torció la mano a la duda escéptica mostrando a través de la llamada "duda metódica" que en la misma duda hay un saber profundo. Que en ella, como forma del pensamiento hay un saber fundamental de la existencia. Este es el sentido del conocido apotegma: pienso, luego existo, cogito ergo sum.

Descartes dirá que el pensamiento, en la medida en que abre a la existencia, constituye esencialmente al hombre. Volvemos, pues, a encontrar al hombre definido por su inteligencia ahora en ese otro lema cartesiano, res cogitans, sustancia que piensa. Pensar, para Descartes, es una acción de infinitas dimensiones expuesta de partida a la duda y al error. Es en este campo de posibilidades que se abren ante el hombre y a las que la inteligencia se ve volcada, donde la voluntad campea como una potencia indefinida. Esta realidad, que puede ser caótica, alcanza su equilibrio y perfección, según Descartes, justo ahí donde inteligencia y voluntad se identifican en un acto que paradigmáticamente expresa la sentencia: "pienso, luego existo". Aquí se prueba la capacidad esencial del pensamiento, que es la existencia. $Y$ esta capacidad es la verdad. El saber acerca de la verdad de la existencia descubre quién es el hombre. El hombre es 
el ser que sabe de sí en el ejercicio de su libertad. La libertad revela la verdad de la existencia. Este es el pensamiento de Descartes.

\section{La libertad postula un mundo del espíritu}

Voy a concluir esta presentación volviendo otro poco a la teoría kantiana para destacar la línea divisoria con el pensamiento clásico. Pienso que una nueva concepción de la libertad inaugura el pensamiento moderno. La modernidad, me parece, quisiera definirse a sí misma como "hazaña de la libertad". Pero ¿de qué libertad se trata ahora?

El lenguaje es rico en equívocos. No todo puede ser dicho con palabras propias de cada uno. El lenguaje se ve forzado, entonces, a la diversidad de sentidos de las palabras. Y la primera urgencia del pensar filosófico será la fijación del sentido. Tarea que inicialmente emprende la lógica, pero que no llega a realizar cabalmente por lo que debe ceder el paso a una reflexión que está más allá de la lógica. Es, propiamente, la filosofía.

Bien, la libertad se torna gravemente equívoca en los tres últimos siglos. Y el equívoco reclama ir a sus raices que es tarea del pensar filosófico.

En Aristóteles y Descartes la libertad fue concebida como el dinamismo espiritual que define la realidad concreta del hombre a la que el griego llamó con esta palabra que pareciera en definitiva intraducible justo porque se nombra a sí misma: logos. Para medir todo el alcance que la noción tomará recuérdese que San Juan, en la necesidad de nombrar a Cristo en el comienzo de su Evangelio, le llama Logos, Verbo. San Juan dijo que el Verbo es lo que está en el principio. Dio al logos, que los griegos vieron como esencia del hombre, una dimensión divina.

Kant va a hablar, esencialmente, de la Razón, como advierten los títulos de sus dos obras principales a las que llama críticas de la razón. ¿Qué sentido tiene la crítica de la razón en el pensamiento de Kant?

Kant estaba bajo el impacto fascinante de la ciencia moderna, que había alcanzado en el pensamiento de Newton su apogeo. Era un saber de pura índole físicomatemática que había abierto un impresionante camino progresivo y cuyas posibilidades de desarrollo Kant previó. ¿Cuáles son sus condiciones de posibilidad? se preguntó entonces. Y en la Crítica de la Razón Pura dejó establecido que esas condiciones son la estructura teórica de la razón, que pasa por un proceso de deducción trascendental y formula las leyes de la naturaleza. La ciencia moderna parecía quedar claramente explicada en sus fundamentos operativos por el pensamiento de Kant que rige todavía toda epistemología.

En esta teoría kantiana acerca del conocimiento científico quedaba fuera algo que el propio Kant consideraba como el interés soberano de la razón. Y éste radicaría, más bien, en un saber acerca de la naturaleza espiritual del hombre; de la inmortalidad de su alma y de la existencia de Dios. Justamente los temas que las Meditaciones de 
Descartes habían hecho suyos y que figuran en el subtítulo del libro de Descartes. Kant tenia una profunda preocupación por estos asuntos. Pero pensó que eran inaccesibles a un saber teórico.

La inteligencia no sería capaz de conocer realmente las cosas, de situar al hombre en la realidad. Sólo puede operar una deducción trascendental de los datos de la sensibilidad. Kant creyó necesario, entonces, abolir un saber teórico acerca de seres reales, para hacer lugar, dijo, a la fe. Y este lugar lo abrió, justamente, a partir de la libertad. Kant concibió, pues, la libertad condicionada por el compromiso teórico que le vedaba el saber de una naturaleza real. Seres reales últimamente serían tan sólo seres puramente espirituales, como el alma y Dios, con lo cual el idealismo sentó su tesis básica.

Kant va a situar, entonces, el punto de partida de la moral en un dato de la conciencia pura: la conciencia del deber. Nos sentimos naturalmente obligados a algunas cosas que debemos hacer u omitir como efecto de la voz espiritual de la conciencia. Kant dice que la razón esencial de esa forma de conciencia es la libertad y que este es un un factum que se torna ley por sí misma. Esta ley se expresa en un imperativo autónomo de acuerdo con el cual uno debe obrar de tal manera que su conducta pueda constituirse como ley universal. Uno se torna legislador de sí mismo y legislador universal. La libertad se convierte en razón imperativa universal pero radicada fuera de la naturaleza, fuera de la realidad, en un mundo suprasensible que el hombre postula desde una conciencia pura de sí mismo.

\section{La aporía actual.}

Después de Kant, pero a la sombra suya, se despojará a la libertad de los rasgos de una imperativa racionalidad universal. Se guardará solamente la autonomía de un núcleo subjetivo sin rostro, sin conexión con ninguna realidad, convertido en imperativo fáctico, en voluntad pura. La libertad es un poder ante sí mismo que uno mismo regula; yo soy mi propia ley. Así se está pensando en el fondo cuando, por ejemplo, se oye decir: obro en conciencia, soy libre para pensar como quiero y para hacer lo que quiera, sin otra limitación que la posibilidad del otro de hacer lo mismo que cabe conceder por las mismas razones. Soy absolutamente libre hasta el límite de la libertad del otro. Aunque no resulta difícil traspasar esta frontera porque en definitiva no conozco bien cuál es la libertad del otro.

He ahí, pues, dos concepciones de la libertad con mucho en común pero en esencia distintas. La libertad como fruto de una acción virtuosa arraigada en la misma naturaleza de un ser real cuya perfección procura. Es el pensamiento de Aristóteles y Descartes. Y la libertad como factum despojado de toda condición real, que se erige como imperativo autónomo de un sujeto trascendental. Es el pensamiento de Kant.

Creo que la experiencia histórica de la libertad ha sido vivida bajo ese doble signo. Y que la postulación por Kant de la autonomía de un sujeto ha conducido a una pérdida del sentido de la libertad, la cual, en definitiva, se convierte en nada más que voluntad de poder y nihilismo, que es lo que presenciamos. 
Después de esa doble experiencia histórica y al concluir este siglo ¿Qué nos queda? ¿O hemos quedado con las manos vacías? Me atrevería a decir que la respuesta ha de estar marcada por una señal: ser ella misma una acción libre de la inteligencia ¿Caemos en un círculo? No. Sólo la libertad permite hablar de ella misma como esa inteligencia deseosa que, al decir de Aristóteles, es la naturaleza del hombre. La libertad es, en efecto, el factum de la existencia del hombre que la inteligencia carga de sentido.

La libertad es un factum, como dijera Kant, traspasado por la inteligencia. Aristóteles, Descartes y Kant así lo reconocieron. Pero Kant sacrificó a la inteligencia en el altar de la ciencia moderna. La sacrificó partiéndola en dos: una que descifra la experiencia sensible y otra que postula un mundo del espíritu. El primero es el campo de la teoría; el segundo, el de la práctica. Mundos distintos, separados, extraños entre sí. En la línea del pensamiento de Aristóteles, en cambio, la unidad esencial de inteligencia y voluntad determinan al hombre como un ser libre en el mismo seno de la naturaleza. Esta es la aporía de la libertad que está planteada en la base misma de nuestro mundo moral. 